\title{
A mobilização da memória discursiva no movimento ciberfeminista: análise da hashtag \#metoo
}

DOI: http://dx.doi.org/10.21165/el.v48i3.2223

\section{Julia Lourenço Costa ${ }^{1}$}

\section{Resumo}

O assédio, que faz parte das temáticas específicas abordadas pelo movimento social feminista (HIRATA et al., 2009), será discursivamente analisado neste artigo a partir da irrupção e circulação da hashtag \#metoo \#eutambém, que tomou as redes sociais no final de 2017. Ancorados na Análise do discurso francesa, mobilizaremos as noções de memória e des-memória discursivas (PAVEAU, 2013a, 2013b, 2015, 2017) procurando depreender como essas noções contribuem para instauração da polêmica como interincompreensão (MAINGUENEAU, 2008), isto é, gerando uma espécie de dissenso, manifestado a partir de diversas posições enunciativas. O movimento feminista tem ganhado cada vez mais força no ciberespaço, onde o chamado ciberfeminismo (LALONDE, 2012) vem se apropriando das ferramentas virtuais disponíveis. A hashtag, enquanto tecnopalavra (PAVEAU, 2017), participa da argumentação ciberativista como ponto de ancoragem do debate público acerca de determinada temática; portanto a hashtag é encarada, neste artigo, como sintetizadora de questões político-ideológicas.

Palavras-chave: ciberativismo; ciberfeminismo; memória discursiva; des-memória discursiva; polêmica.

1 Universidade Federal de São Carlos (UFSCar), São Carlos, São Paulo, Brasil, julialourenco@usp.br; https://orcid.org/0000-0001-8571-8879 


\title{
The mobilization of discursive memory in the cyberfeminist movement: analysis of the hashtag \#metoo
}

\begin{abstract}
The harassment, which is part of the specific thematic approached by the feminist social movement (HIRATA et al., 2009), will be discursively analyzed in this article from the irruption and circulation of the hashtag \#metoo, which took the social networks at the end of 2017. Anchored in French Discourse Analysis, we will mobilize the notions of discursive memory and des-memory (PAVEAU, 2013, 2013a, 2015, 2017) seeking to unravel how this notions contribute to the establishment of polemic as interincomprehension (MAINGUENEAU, 2008), generating a kind of dissent, manifested from different enunciative positions. The feminist movement has gained more strength in cyberspace, where the so-called cyberfeminism (LALONDE, 2012) has appropriated the available virtual tools. The hashtag, while techno-word (PAVEAU, 2017), functions in cyber activism as an anchoring point of the public debate about a certain theme; therefore the hashtag is stared, in this article, as a synthesizer of political-ideological questions.
\end{abstract}

Keywords: cyber activism; cyberfeminism; discursive memory; discursive des-memory; controversy.

\section{Notas sobre o espaço digital}

O espaço digital, de acordo com Pierre Lévy (1999), é um dos principais novos meios de comunicação, sendo a internet encarada como parte das tecnologias digitais e funcionando enquanto infraestrutura das comunicações no ciberespaço. Nela, são criados diversos ambientes virtuais de interação, que reconstroem as relações intersubjetivas, agora mediadas pela máquina.

O autor define o ciberespaço como "novo meio de comunicação que surge da interconexão mundial de computadores" (LÉVY, 1999, p. 17) e, a partir de tal compreensão, pretendemos neste trabalho refletir sobre o ativismo que se consolida neste espaço de interação social, definido pela troca virtual simbólica. Nosso olhar científico-analítico incidirá especificamente na constituição, consolidação e circulação dos discursos que se inserem no chamado movimento ciberfeminista.

Dentre outras características, o ciberespaço determina uma nova relação com o tempo e com o espaço, além da própria reformulação da interação intersubjetiva. O sujeito, já antes concebido como heterogêneo, extrapola na internet sua constituição plural e dialógica, ao mesmo tempo em que sua busca de pertencimento à determinada comunidade se torna mais incessante. 
Os movimentos sociais têm cada vez mais ganhado força de circulação no ciberespaço, que funciona como amplificador on-line das causas já debatidas off-line. O poder da internet está, em certa medida, relacionado à capacidade do comportamento humano e de suas perspectivas sobre a realidade serem refletidas em ambiente digital, daí o surgimento do termo cibercultura, como relação entre sociedade, cultura e ambiente eletrônico virtual.

$\mathrm{Na}$ internet, diversas instituições discursivas produzem e circulam sentido e, se verifica, contemporaneamente, a proliferação das manifestações relacionadas aos movimentos sociais que - assim como a própria sociedade - estão em constante transformação. O ciberativismo, como processo de adaptação dos movimentos sociais às novas tecnologias, tem contribuído não só na divulgação das variadas causas sociais, políticas e econômicas, mas na própria determinação destes movimentos reivindicatórios.

De acordo com Castells $(2001,2017)$, as lutas sociais foram historicamente marcadas por movimentos sociais que mantinham certa cadeia hierárquica alinhada aos valores verticalizados do processo de industrialização. Por outro lado, o que se assiste hoje com o ciberativismo é a horizontalização das lutas contemporâneas, que passam a ter uma estrutura marcada pelo acesso mais democrático proporcionado pela rede.

A internet se configura como ferramenta para as lutas sociais contemporâneas e é concebida como espaço potencial de expressão e participação genuinamente democrática ${ }^{2}$ (DEIBERT, 2000). Tal ferramenta viabiliza a união e a mobilização das variadas comunidades discursivas ${ }^{3}$, além da promoção horizontalizada das informações,

2 "Com relação aos prós e contras dessa apropriação social da técnica, as opiniões estão divididas. Como demonstra Deibert (2000), a posição otimista, sustentada por teóricos de influência Gramsciana (COX, 1999) e Liberal (FALK, 1992; 1995), acredita que as redes de cidadãos constituem uma potencial expressão de participação genuinamente democrática, nas arenas até então monopolizadas pelo Estado e por corporações transnacionais; sendo que a Internet é considerada essencial para que essas redes se desenvolvam (p. 256). Por outro lado, há teóricos que sustentam o argumento de que, longe de se tornarem uma expressão da democracia, essas redes de cidadãos baseadas na Internet conduzem a uma ruína democrática em escala global; pelo fato de permitirem que muitos interesses diferentes ou, até mesmo contraditórios, sejam discutidos em nível internacional sem nunca se alcançar nenhuma meta - mas causando um enorme 'engarrafamento' de idéias, posições e visões de mundo - nem sempre positivas (RIEFF; CLOUGH apud DEIBERT, 2000, p. 256). Além disso, existem outros autores que defendem que as verdadeiras ações coletivas estão baseadas em relações face-a-face, sendo que a partir da Internet não é possível obterem sucesso (TARROW, 2002)." (RIGITANO, 2003).

3 "Na problemática de Maingueneau (1984, 1987), a noção de comunidade discursiva é solidária à de formação discursiva. Efetivamente, a hipótese subjacente é que não basta opor as formações discursivas em termos puramente textuais: de um discurso a outro, "há mudança na estrutura e no funcionamento dos grupos que gerem esses discursos" (1984, p. 135). Em outros termos, os modos de organização dos homens e de seus discursos são indissociáveis; as doutrinas são inseparáveis das instituições que as fazem emergir e que as mantêm" (MAINGUENEAU; CHARAUDEAU, 2008, p. 108). 
que passam a ser difundidas de lugares discursivos cada vez menos marcados pela hierarquia das relações sociais.

\section{A relação entre ciberespaço, linguagem e feminismo}

A partir da ocupação também dos espaços digitais, as mulheres reivindicam seu espaço social e contribuem com a luta feminista de outrora: da primeira onda (final do século XIX, início do século XX), que questionava o direito de igualdade a homens e mulheres a partir dos direitos humanos; da segunda onda (até 1970), que se preocupou, em linhas gerais, em definir o que é ser mulher e da terceira onda (1990), marcada pela reflexão interna ao próprio movimento e preocupação com outras categorias socialmente excluídas. ${ }^{4}$

A chamada quarta onda do movimento feminista, o feminismo em sua versão digital, ou ainda o chamado ciberfeminismo, apesar de escancarar o próprio movimento enquanto movimento heterogêneo, mantém um núcleo comum determinado pela defesa da identidade e do papel social da mulher segundo novos paradigmas. De acordo com Lalonde (2012),

[...] o ciberfeminismo éuma das importantes manifestações do ativismo na internet. O termo ciberfeminismo apareceu nos anos 1990, emergindo simultaneamente de fontes diferentes. Compreendemos, habitualmente, que o surgimento do termo foi em 1992, nas manifestações artísticas do VNS Matrix na Austrália e nos trabalhos teóricos de Sadie Plant. Portanto, é nos anos 2000 que o ciberfeminismo eclode em toda sua complexidade, juntamente com o crescimento da acessibilidade da Web. 0 termo ciberfeminismo evolui rapidamente e se desenvolve em diferentes frentes, abarcando problemáticas variadas que poderíamos reagrupar sob a compreensão geral enquanto relação entre as mulheres e a tecnologia, a partir de uma perspectiva feminista.

Analisar a produção discursiva do ciberfeminismo permite vislumbrar o modo como as novas relações sociais estão sendo erigidas por meio da linguagem, pois, pelas redes sociais, as mulheres (re)constroem e defendem seus espaços no "mundo público", anteriormente a elas negado. A internet dissolve algumas barreiras e permite um modo de expressão feminista menos limitado.

Da perspectiva linguística, podemos apreender a comunicação midiática por meio da construções textuais que circulam, concebendo a linguagem como mediação necessária entre o homem e a realidade natural, histórica e social. Especificamente do mirante

4 Sobre as chamadas "ondas" do movimento ciberfeminista, consultar, por exemplo, ALVES, B. M.; PITANGUY, J. O que é feminismo. Coleção Primeiros Passos. São Paulo: Brasiliense, 1991 e PINSKY, C. B.; PEDRO, J. M. (org.). Nova história das mulheres no Brasil. São Paulo: Contexto, 2018. 
teórico que adotamos na pesquisa, qual seja, a Análise do discurso francesa, temos como compreensão inicial que ela

[...] não trata da língua, não trata da gramática, embora essas coisas lhe interessem. Ela trata do discurso. E a palavra discurso, etimologicamente, tem em si a ideia de curso, de percurso, de correr, de movimento. 0 discurso é assim palavra em movimento, prática de linguagem: com o estudo do discurso observase o homem falando. (ORLANDI, 2007, p. 15).

Ainda na esteira de se pensar a linguagem enquanto discursiva, podemos afirmar que, se por um lado, a língua é um sistema, ou seja, ela se constitui como rede interna estruturante das relações entre os elementos linguísticos; por outro, como discurso, podemos concebê-la como "combinações de elementos linguísticos [...] usadas pelo falante com o propósito de exprimir seus pensamentos, de falar do mundo exterior ou de um mundo interior, de agir sobre o mundo" (FIORIN, 2004, p. 11).

Assim sendo, a língua, enquanto discurso, constrói a realidade por meio dos mecanismos de linguagem, e é também por esse mecanismo que podemos refletir acerca da construção do nosso tema de pesquisa, apresentado em linhas gerais neste texto, a saber, a construção discursiva do movimento denominado ciberfeminismo, apreendendo o discurso como forma de inscrição ideológica no mundo e representação da realidade pretendida.

Da perspectiva discursiva, a língua é, para além de uma estrutura, um ponto de encontro entre uma estrutura (atualização do sistema linguístico) e um acontecimento (o retorno da memória discursiva como dito), como afirmado anteriormente. Além disso, é um modo de o sujeito imprimir sua identidade, uma vez que, por meio dela, ele é capaz de se expressar segundo seu próprio ponto de vista em relação às coisas do mundo, sendo que

[...] o texto se organiza e produz sentidos, como um objeto de significação, e também se constrói na relação com os demais objetos culturais, pois está inserido em uma sociedade, em um dado momento histórico e é determinado pelas formações ideológicas especificas, como um objeto de comunicação. (BARROS, 2011, p. 188).

A concepção discursiva, que imbrica discurso e posicionamento ideológico, remete, a nosso ver, a uma impressão moralizante efetuada no discurso acerca da realidade linguisticamente construída. Se o sujeito fala de determinado lugar e espaço históricosocialmente determinados, ele imprime sua visão de mundo, ideologicamente determinada. 
Algumas construções discursivas podem escancarar a axiologia que fundamenta a avaliação moralizante dos discursos segundo os valores que devem ser euforizados e disforizados. Os realces efetuados pelo sujeito (em títulos, aforizações, hashtags, por exemplo) visam condensar seu ponto de vista crítico acerca de determinado tema, ressaltando os valores de bem e rechaçando, ou apagando, os valores de mal.

A determinação dos papéis sociais referentes à construção do gênero (homem e mulher $)^{5}$, por exemplo, é carregada de implicações morais, culturais e sociais. Com as construções discursivas acerca da temática do assédio não poderia ser diferente: elas estão contaminadas pelas determinações ideológicas que permeiam tal isotopia.

Donna Haraway (1984), inspiradora do movimento ciberfeminista, reconhece que é difícil nomear um movimento tão multiforme como o feminismo, que abarca em si uma diversidade de sujeitos, que podem reconstruir a realidade por meio do discurso de formas variadas. A autora afirma que "a consciência da exclusão que é produzida por meio do ato da nomeação é aguda. As identidades parecem contraditórias, parciais e estratégicas" (HARAWAY, 1984, p. 47).

Apesar de se constituir enquanto movimento heterogêneo, o feminismo em rede mantém um núcleo comum, determinado pela defesa da identidade e do papel social da mulher segundo novos paradigmas. Ele emerge a partir do "esforço e da importância de estabelecer uma rede de comunicação entre as mulheres" (COLLADO; NAVARRETE, 2006), uma vez que é a partir do debate, do diálogo e da circulação das ideias que os movimentos sociais tomam forma e se fortalecem.

Uma das manifestações deste feminismo, enquanto movimento social heterogêneo, é o próprio ciberfeminismo, determinado pela ocupação das mulheres dos espaços sociais, doravante redesenhados pelo espaço da web. Os ideais feministas, mantidos em sua essência, procuram, portanto, ser preservados no espaço virtual, no qual cada vez mais as mulheres têm não só se manifestado de modo passivo - utilizando as ferramentas já disponíveis -, mas de modo ativo (atuando cada vez mais na área de tecnologia e informática) ${ }^{6}$.

5 Salientamos que neste texto não temos como objetivo abordar questões contemporâneas acerca dos limites e limiares relacionados à concepção binária de gênero.

6 Existem diversos grupos em todo o mundo que discutem a relação da mulher com a criação e gerenciamento de novas tecnologias. Citamos alguns: Rail Girls, Women who code, PyLadies, Code Girls, MariaLab, Women TechMakers, Womoz, Meninas Digitais, Mulheres na tecnologia, Technovation, dentre outros. 


\section{0 assédio sexual como tema feminista}

O espaço virtual exacerba o caráter já heterogêneo do movimento feminista e, cada vez mais, fala-se em feminismos - no plural. De acordo com Hirata et al. (2009), é possível afirmar que o fator de unificação do feminismo reside na centralidade observada na problemática da dominação entre os sexos e suas consequências. De modo geral, a reivindicação por uma sociedade mais igualitária entre homens e mulheres é o tema central da agenda feminista.

Tal temática principal se decompõem em subtemas relacionados, tais como, as questões em torno do corpo feminino (que envolvem desde a liberdade de escolha do vestuário até a descriminalização do aborto); a relação entre cidadania e gênero; as diferenças biológicas e as implicações na ascensão profissional no mercado de trabalho; a disparidade na dedicação ao trabalho doméstico; a desigualdade na educação e socialização; os vestígios do patriarcado; a violência contra a mulher, etc.

Dentre os temas que fazem parte do escopo traçado pelo feminismo encontra-se o assédio, que pode ser definido como "condutas de natureza sexual, quer sejam de expressão física, verbal ou não-verbal, propostas ou impostas a pessoas contra sua vontade [...], e que acarretam um ataque à sua dignidade (HIRATA et al. 2009, p. 26).

Neste artigo, nosso olhar incidirá sobre o assédio sofrido por mulheres na relação direta com o desenvolvimento profissional. De acordo com Rago (1997, p. 578), "os direitos de utilização dos corpos das mulheres, aí compreendidos evidentemente em sua dimensão sexual, foram perpetuados no seio das relações salariais". Pretendemos refletir sobre a temática do assédio, na medida em que ela afeta diretamente as mulheres não só no espaço privado ou público, mas também no ambiente profissional.

O processo mais amplo de inserção das mulheres no mercado de trabalho ocorreu principalmente durante as grandes guerras mundiais - momentos nos quais a figura feminina esteve fortemente relacionada ao empoderamento. Porém, os altos cargos continuavam sendo ocupados majoritariamente por homens, fato que, da perspectiva salarial e da ascensão profissional, determinavam a figura da mulher enquanto corpo a ser negociado.

A noção de assédio sexual foi desenvolvida por feministas da Universidade de Cornell nos anos 70, a partir da observação das práticas no contexto das relações de trabalho. No campo jurídico, o assédio sexual é definido no artigo 216-A da Constituição como "[...] ato de constranger alguém com o intuito de obter vantagem ou favorecimento sexual, prevalecendo-se o agente da sua condição de superior hierárquico ou ascendência inerentes ao exercício do emprego, cargo ou função" (Artigo 216-A, incluído pela Lei $n^{\circ} 10.224$, de 2001). 
Apesar do assédio sexual poder atingir homens e mulheres, estas, segundo FACURI (2013) são as principais vítimas. De acordo com o Datafolha - Instituto de pesquisas, $42 \%$ das mulheres brasileiras já sofreram assédio sexual. Ainda segundo a pesquisa, 22\% das mulheres já sofreu algum tipo de assédio no transporte público; 15\% já sofreu assédio no trabalho; $10 \%$ foram assediadas sexualmente na escola ou faculdade e $6 \%$ em casa. ${ }^{7}$

O assédio vivido cotidianamente há décadas pelas mulheres é uma das temáticas abordadas pelo ciberfeminismo. A partir do uso de todos os recursos tecnológicos disponíveis, as mulheres passaram a ocupar o espaço virtual criando fóruns de debates, grupos nas redes sociais, publicações, compartilhamentos, memes, caricaturas, etc.. Nosso objeto específico, neste trabalho, refere-se à apropriação da hashtag pelo movimento ciberfeminista. A hashtag pode ser definida enquanto

\begin{abstract}
[...] segmento de linguagem precedido do símbolo \#, utilizado originalmente na rede Twitter, mas adaptado a outras plataformas, como o Facebook. Essa associação faz com que se torne uma tag clicável, inserida manualmente no Twitter que permite acessar um fio que reúne o conjunto dos enunciados que contém a hashtag [...]. (PAVEAU, 2017, p. 196).
\end{abstract}

Nosso olhar, neste momento, incidirá especialmente na reflexão sobre o funcionamento da hashtag como dispositivo tecnolinguageiro (PAVEAU, 2017) utilizado pelos movimentos sociais na internet. De acordo com a referida autora, "a hashtag é uma convenção criada pelos usuários da rede" (KWAK et al. 2010). É uma forma tecnolinguageira cuja função é essencialmente social, permitindo afiliação difusa" (PAVEAU, 2017, p. 197).

A hashtag desempenha relevante papel no chamado ciberativismo e a tentativa de desenhar um percurso acerca dos usos desta ferramenta no ativismo feminista virtual permite refletir acerca do processo mais amplo de criação de uma forma reiterável, que pode ser utilizada por vários usuários e que, pode ainda, ser reformulada mantendo a mesma estrutura. A hashtag funda uma comunidade discursiva e delimita a defesa de determinada visão de mundo, na mesma medida em que se abre ao diálogo e à polêmica.

Ancorados, portanto, na Análise do discurso francesa, pretendemos refletir acerca da criação, uso e circulação da hashtag enquanto dispositivo tecnolinguageiro (PAVEAU, 2017), abordando especificamente a \#metoo (\#eutambém, em português), que tomou

7 Para mais informações: http://datafolha.folha.uol.com.br/opiniaopublica/2018/01/1949701-42das-mulheres-ja-sofreram-assedio-sexual.shtml. Acesso em : 15 jan. 2018. 
conta da internet em outubro de 2017 acerca dos casos de assédio sexual sofridos por mulheres no seu ambiente de trabalho e em nas relações profissionais em Hollywood. ${ }^{8}$

Tendo tais questões no horizonte, salientamos que nosso interesse principal neste artigo foi enfatizado pela circulação mundial da hashtag \#metoo: em apenas dois dias ela foi usada mais de 200 mil vezes nas redes sociais ${ }^{9}$. 0 alcance de tal hashtag tem relevância não apenas em relação à quantidade em que foi replicada nas redes, mas principalmente devido à visibilidade proporcionada à pauta mais ampla e complexa do próprio movimento feminista: o assédio sofrido por mulheres, especialmente no ambiente de trabalho.

\section{A mobilização da memória discursiva do assédio: \#metoo}

Refletiremos cientificamente sobre o funcionamento discursivo da hashtag \#metoo ancorados no referencial teórico da Análise do discurso, contemplando especificamente as noções de memória e des-memória discursivas (PAVEAU, 2013) como mecanismos linguístico-discursivos engendrados na construção do sentido. A partir da mobilização da memória discursiva do assédio ou da tentativa de apagamento desta linhagem discursiva - ambas determinadas pelas formações discursivas específicas - há a instauração da polêmica como interincompreensão (MAINGUENEAU, 2008).

A \#metoo foi amplamente disseminada na web em decorrência das denúncias de assédio, feitas pela atriz americana Ashley Judd, contra o magnata do cinema Harvey Weinstein. As denúncias foram feitas na reportagem intitulada Harvey Weinstein pagou acusadores de assédio sexual por décadas, ${ }^{10}$ publicada em 5 de outubro de 2017 na versão on-line do jornal The New York Times.

Na referida reportagem, é narrativizado o modus operandi dos episódios de assédio de Weinstein: ele convidava as mulheres para um hotel e lá praticava os abusos. Muitas o acusaram de assédio, dentre elas uma funcionária temporária (que trabalhou apenas um

8 É importante assinalarmos que o feminismo é cada vez mais heterogêneo e plural e que muitas mulheres (asiáticas, negras e latinas, por exemplo) não se sentem representadas pelas hashtags que circulam na web. Além disso, é necessário, ainda, ter consciência de que a referida hashtag pode ter alcançado posição de destaque devido ao fato de estar relacionada a atores sociais expostos pela mídia.

9 Em reportagem sobre o tema, o site da BBC afirma, em 17/10/2017, que "A hashtag \#MeToo já foi usada mais de 200 mil vezes nas redes sociais". Ela havia sido primeiramente publicada dois dias antes. Disponível em: http://www.bbc.com/portuguese/internacional-41652306. Acesso em: 10 abr. 2018.

10 Tradução nossa do título original em língua inglesa: "Harvey Weinstein Paid Off Sexual Harassment Accusers for Decades". Disponível em: https://www.nytimes.com/2017/10/05/us/harvey-weinsteinharassment-allegations.html. Acesso em: 09 mar. 2018. 
dia na empresa) e uma assistente; mas a denúncia que alavancou os processos foi feita pela atriz americana Ashley Judd ${ }^{11}$.

No dia 15 de outubro, a \#metoo foi lançada pela atriz Alyssa Milano que sugeriu, em sua conta pessoal no Twitter, que os usuários empregassem tal hashtag para compartilhar suas próprias experiências de assédio. Essa sugestão foi feita como manifestação de apoio às denúncias de assédio em Hollywood que não pararam de crescer ${ }^{12}$. A seguir é possível observar a publicação fundadora da referida hashtag no Twitter de Milano:

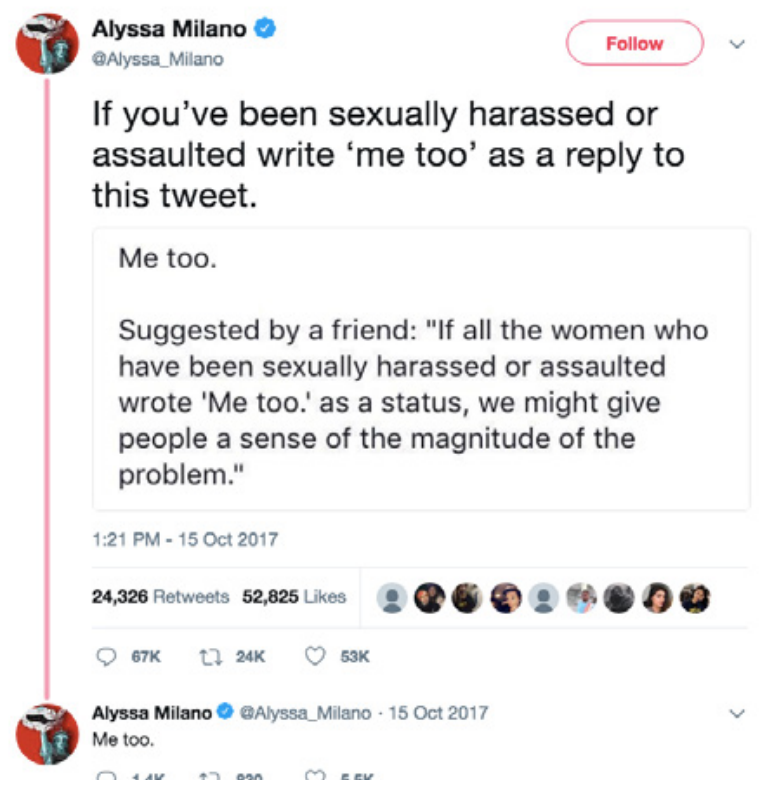

Figura 1. Twitter Alyssa Milano

Fonte: Twitter

As hashtags funcionam a partir da mobilização de uma memória discursiva, mais específica e atual - as denúncias que circularam na web em torno do casos de Hollywood

11 Para mais informações, consultar a referida reportagem (link de acesso na nota de rodapé anterior). A título de exemplo, transcrevemos a seguir um trecho da reportagem: "Duas décadas atrás, o produtor de Hollywood Harvey Weinstein convidou Ashley Judd para o Peninsula Beverly Hills Hotel, para o que a jovem atriz esperava ser um café da manhã de negócios. Em vez disso, ele a mandou subir para seu quarto, onde apareceu com um roupão e perguntou se ele poderia massageá-la ou se ela poderia observá-lo tomar banho, ela relembra na entrevista: "Como eu poderia sair desse quarto o mais rápido possível sem perturbar Harvey Weinstein? Srta. Judd disse se lembrar desse pensamento" (New York Times, on-line, 5/10/2017 - tradução nossa do original em língua inglesa).

12 No dia 10 de outubro de 2017, o New York Times publica nova reportagem afirmando que as atrizes Gwyneth Paltrow e Angelina Jolie se juntaram às acusações de assédio contra Harvey Weinstein. Disponível em: https://nyti.ms/36iw9tV. Acesso em: 07 dez. 2017. 
- e uma memória discursiva mais ampla e histórica (a que mais nos interessa): o assédio sofrido pelas mulheres devido à desigualdade de gêneros e à dominação masculina na sociedade.

A hashtag \#metoo pode ser compreendida enquanto acontecimento discursivo na medida em que instaura a relação entre "o passado, a memória e a história" (MAINGUENEAU; CHARAUDEAU, 2008, p. 29). Implicitamente ao enunciado da hashtag, "eu também" (\#metoo), que condensa: "eu também sofri assédio ou fui agredida", ou ainda "eu também apoio a causa", está a temática mais ampla do assédio sofrido pelas mulheres ao longo da história.

Ao escrever \#eutambém o enunciador inscreve seu discurso na memória discursiva do assédio, neste caso especificamente acerca dos abusos de poder sofridos pelas mulheres no ambiente de trabalho e/ou nas relações profissionais. A hashtag \#metoo produz um elo de memória na medida em que insere os discursos que a mobilizam no fio determinado pela história da temática do assédio.

Reitera a memória discursiva do assédio e continua operando pela categorização do acontecimento de acordo com a linhagem discursiva do assédio, as publicações das (dos) internautas em resposta ao primeiro tweet da atriz. Tais publicações se alinham à memória discursiva do assédio - consequentemente se colocam em posição de repúdio aos abusos cometidos em Hollywood - como é possível observar a seguir ${ }^{13}$ :

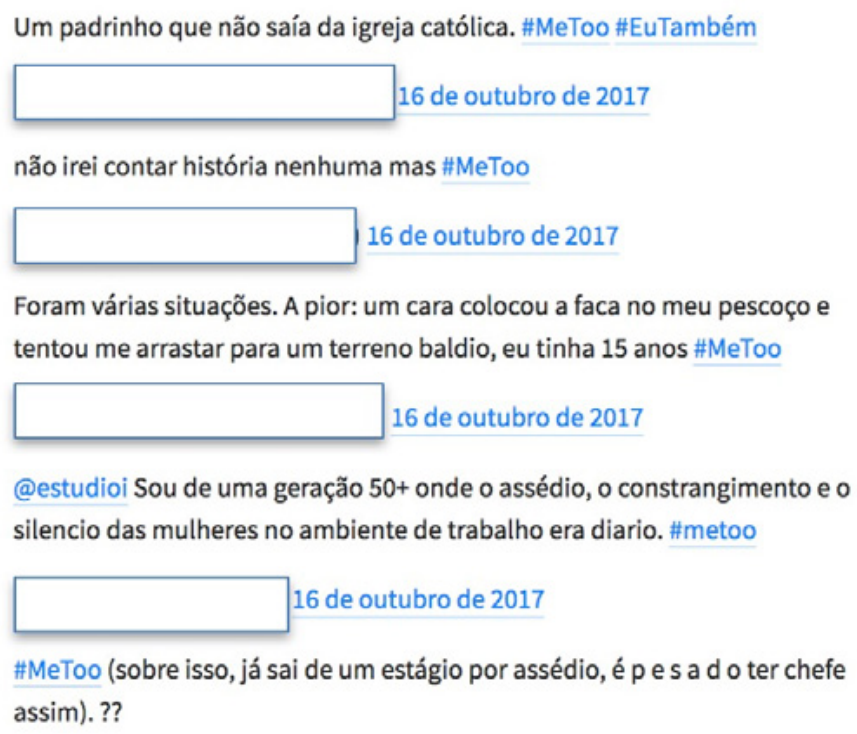

Figura 2. Exemplos de tweets com as hashtags \#metoo \#eutambém

Fonte: Disponível em: https://bit.ly/2Nrg9gy.- Acesso em: 15 mar. 2019

13 Os exemplos das publicações das usuárias do Twitter com as hashtags \#metoo \#eutambém foram extraídos do site Tecnomundo. 
Nas publicações é possível verificar a recorrência de semas como "assédio" e "abuso", os quais funcionam como pré-construídos no funcionamento da hashtag \#metoo. De acordo com Maingueneau e Charaudeau (2008, p. 401), "a noção de pré-construído está intimamente ligada à de interdiscurso", interdiscurso este mobilizado pela recorrência à memória discursiva do assédio. Ainda, de acordo com Paveau (2013, p. 113-114):

[...] na perspectiva da cognição social, versão distribuída, coloco a natureza cognitivo-discursiva da memória no discurso. Isso implica renunciar às imagens estereotipadas da memória como simples armazenamento ou dicionário, para torná-la um agente ativo na produção de discursos. Se ela registra ou 'acumula' efetivamente os sentidos, a memória cognitivo-discursiva também elabora e constrói os sentidos, principalmente, pela operação de categorização.

A mobilização da memória discursiva do assédio pela disseminação da \#metoo \#eutambém foi empreendida pela própria mídia, que inseriu o debate suscitado pela referida hashtag na temática mais ampla do assédio sexual, operando a partir desta categorização semântica. Esse fato pode ser observado nos títulos de algumas reportagens publicadas à época, tais como, "'Eu também, a campanha global que chama a atenção sobre a magnitude do assédio contra mulheres"14; "Milhares dizem 'eu também' à 'pesquisa' da atriz Alyssa Milano sobre assédio sexual"15; "\#EuTambém surge da impunidade e da cultura do silêncio em relação à violência sexual, diz ONU"16; "\#EuTambém: Mulheres do mundo contam que sofreram assédio sexual"17, que são alguns poucos exemplos.

De acordo com Paveau (2013, 2017), situações discursivas semelhantes, como a reiteração da hashtag na internet, operam de acordo com a categorização, isto é, ao utilizar a \#metoo o sujeito insere seu discurso na temática do assédio, na mesma medida em que a ressignifica e promove sua circulação. A memória, de uma perspectiva cognitivodiscursiva participa, portanto, da produção do discurso:

14 HUFFPOST DO BRASIL. 'Eu também': A campanha global que chama atenção sobre a magnitude do assédio. Disponível em: https://bit.ly/34cptfo. 2017. Acesso em: 31 out. 2018.

15 G1. Milhares dizem 'eu também' à 'pesquisa' da atriz Alyssa Milano sobre assédio sexual. Disponível em: https://glo.bo/2WoaRXj. 2017. Acesso em: 31 out.2018.

16 ONUBR. \#EuTambém surge da impunidade e da cultura do silêncio em relação à violência sexual, diz ONU. 2017. Disponível em: https://bit.ly/2plO4ze. Acesso em: 31 out. 2018.

17 EL PAís. \#EuTambém: Mulheres do mundo todo contam que sofreram assédio sexual. Disponível em: https://brasil.elpais.com/brasil/2017/10/16/estilo/1508163687_006817.html. 2017. Acesso em: 31 out. 2018. 
[...] o trabalho da memória gera situações discursivas semelhantes, que permitem essa extensibilidade semântica das palavras e das fórmulas, aplicáveis a novas situações pelo único fato de que elas foram aplicadas a situações antigas. Essa forma de repetição, longe de ser estéril, éum modo de categorização da experiência nos discursos que se pode chamar de conhecimento por reconhecimento. (PAVEAU, 2013, p. 115).

A categorização, a partir de uma visada linguística faz parte do processo mais amplo da relação estabelecida entre a língua e a realidade, isto é, aquela não se constituindo enquanto espelho desta, mas como possibilidade de representação. A língua estabelece, a partir do signo linguístico, uma relação simbólica com a realidade, isto é, a língua não é o referente (extralinguístico) em si, mas uma construção discursiva que referencia a realidade.

Por conseguinte, pensar a língua como discurso é refletir sobre os mecanismos linguísticodiscursivos que participam da referenciação, da criação, enfım, da categorização da realidade. As diversas posições enunciativas podem ser observadas pelos modos de categorizar o mundo, tais como, as relações entre os papéis atribuídos aos gêneros feminino e masculino, por exemplo, em relação à temática do assédio.

\section{A desmemória discursiva em foco}

Ainda de acordo com a pesquisadora, "a memória no discurso não pode, com efeito, ser apresentada de forma idealista como um conjunto de itinerários harmoniosos e ela deve dar conta igualmente das rupturas, esquecimentos [...]" (PAVEAU, 2013, p. 119). Isto significa que, ao mobilizar determinada memória discursiva, outros fenômenos são abandonados no fio do discurso. A fim de dar conta de tais fraturas, revisões e deslizamentos, Paveau (2013, p. 157) propõe o conceito de des-memória:

[...] chamo de des-memória discursiva um conjunto de fenômenos de discursos que permitem a revisão das linhagens discursivas, isto é, transmissões semânticas cultural e socialmente asseguradas pelas ferramentas de tecnologia discursiva (as placas de rua, por exemplo). Essas revisões podem ser as mudanças semânticas, os neologismos semânticos, as redenominações, as reformulações etc. Em suma, um conjunto de fenômenos linguageiros que vão produzir efeitos transgressivos ou contra-intuitivos em um contexto em que reine um acordo semântico, histórico e até mesmo ético.

Do ponto de vista linguístico-discursivo, as hashtags são encaradas enquanto marcadores rastreáveis, isto é, ao publicar a hashtag o sujeito se integra no debate mais amplo em 
relação à determinada pauta, que está encarnada na própria tecnopalavra ${ }^{18}$. Juntamente com o uso da hashtag na interação virtual, o sujeito procura demarcar seu posicionamento ideológico em torno do tema por ela estabelecido, ao mesmo tempo em que assinala seu pertencimento à determinada formação discursiva.

A hashtag delineia a temática mais ampla na qual ela se insere e, a partir dela, cada enunciador procura inscrever sua visão de mundo (FIORIN, 2004). A partir dos processos de tematização e figurativização, podemos pensar as formas de se construir um discurso sobre a temática do assédio sexual, por exemplo. Cada forma de mobilizar as categorias semânticas de tema e figura remetem a formações discursivas específicas, concretizando modos de pensar e de categorizar o mundo de dado grupo social, de dada comunidade discursiva ${ }^{19}$.

As noções de tema e figura são relevantes para essa discussão teórica, devido ao investimento semântico que oferecem ao discurso, categorizando uma dada realidade, tal como a relação entre os sexos feminino e masculino em relação à temática do assédio. O tema pode ser considerado um "[...] elemento semântico que designa um elemento não presente no mundo natural, mas que exerce o papel de categoria ordenadora dos fatos observáveis." (FIORIN, 2004, p. 24). É, portanto, mais abrangente e menos específico (ou menos concreto) do que a figura, compreendida, por sua vez, como "[...] elemento semântico que remete a um elemento do mundo natural" (FIORIN, 2004, p. 24).

18 "Le hashtag est un technomot (Paveau, 2013a) car il possède une nature composite: le segment est bien langagier (il s'agit de sigles, mots, expressions ou même des phrases entières) mais également cliquable, puisqu'il constitue un lien qui permet la création d'un fil." (PAVEAU, 2017, p. 199).

19 “Na problemática de Maingueneau $(1984,1987)$, a noção de comunidade discursiva é solidária à de formação discursiva. Efetivamente, a hipótese subjacente é que não basta opor as formações discursivas em termos puramente textuais: de um discurso a outro, 'há mudança na estrutura e no funcionamento dos grupos que gerem esses discursos' (1984:135). Em outros termos, os modos de organização dos homens e de seus discursos são indissociáveis; as doutrinas são inseparáveis das instituições que as fazem emergir e que as mantêm. Essa hipótese diz respeito, em primeiro lugar, aos grupos de produtores de textos, que não devem ser considerados como mediadores transparentes. Uma tal hipótese recusa toda interpretação ingênua da distinção entre 〈interior〉 e sexterior〉 de uma formação discursiva. Nessa perspectiva, a noção de comunidade discursiva permite sobretudo caracterizar os locutores, destacando posicionamentos (um jornal, um partido político, uma escola científica...) que são concorrentes em um mesmo campo discursivo. Pode-se, assim, perguntar se a comunidade discursiva deve incluir apenas os produtores de texto ou estender-se àqueles que participam da sua elaboração ou difusão. Pode-se estender a noção a toda comunidade de fala restrita, organizada em torno da produção de discursos, qualquer que seja sua natureza: jornalística, científica, etc. Seus membros compartilham um certo número de estilos de vida, de normas, etc." (MAINGUENEAU; CHARAUDEAU, 2008, p. 108). 
O tema e a figura corroboram discursivamente a percepção que o sujeito tem da "realidade", esta crivada pela linguagem. Assim afirmamos, considerando que os temas "[...] reconstroem o mundo, dado como representação conceitual e simbólica" (DISCINI, 2007, p. 270). Desse modo, determinada temática mais ampla, constitutiva de determinada hashtag, por exemplo, o discurso feminista incorporado na \#metoo \#eutambém, é permeado pela circulação de determinados temas e figuras.

Segundo Fiorin (2009), a formação ideológica é compreendida como visão de mundo, como ponto de vista de um grupo social, e é concretizada pela formação discursiva que, por sua vez, remete ao conjunto de temas e figuras do discurso. Com esse procedimento de apreensão dos movimentos de tematização e figurativização na discursividade, é possível encontrar os vestígios que a enunciação registra acerca de uma formação ideológica discursivizada.

Assim como as próprias formações discursivas são permeáveis, a memória discursiva é atravessada também por des-memórias, isto é, por esquecimentos que fazem parte da constituição do discurso. Da perspectiva da formação discursiva que mobiliza a memória do assédio sexual alinhado ao patriarcado e à dominação masculina da sociedade, há também um processo de des-memória discursiva, quando outros enunciadores promovem o deslizamento do acontecimento discursivo fundado pela hashtag.

No processo discursivo de estabelecimento do debate público em torno da temática do assédio fundado pela hashtag \#metoo \#eutambém, é possível observar a mobilização da des-memória discursiva. A tentativa de reformulação do fio discursivo e temático estabelecido pela hashtag pode ser observada na concretização discursiva a partir dos temas e figuras mobilizados enquanto categorização.

Se de um lado, há enunciadoras que fazem uso da \#metoo \#eutambém a inserindo na temática ampla do assédio sexual, mobilizando temas e figuras a partir da isotopia da opressão vivenciada pelas mulheres face à possibilidade de um ataque, tais como, "faca no pescoço", "terreno baldio", "assédio", "constrangimento", "silêncio" (demonstrados na Figura 2 acima); de outro há mulheres que mobilizam esta tecnopalavra - \#metoo - a partir de outras categorias semânticas.

Em 9 de janeiro de 2018, por exemplo, um coletivo de 100 mulheres francesas, dentre elas a atriz Catherine Deneuve, publicou um manifesto intitulado "Nós defendemos a liberdade de importunar, indispensável à liberdade sexual"20. Neste manifesto, as autoras inserem seu discurso no acontecimento discursivo fundado pela \#metoo, porém o fazem a partir da polarização, isto é, se posicionando de modo contrário, como é possível observar nos trechos a seguir:

20 Tradução nossa do original em língua francesa "Nous défendons une liberté d'importuner, indispensable à la liberté sexuelle". Disponível em: https://bit.ly/2pZ99Q6. 
Na verdade, o \#metoo provocou na imprensa e nas redes sociais uma campanha de denúncia e acusação pública de indivíduos que, sem que lhes tenha sido dada a oportunidade de responder ou de se defender, foram colocados exatamente no mesmo nível que os agressores sexuais. Essa febre [...], longe de ajudar as mulheres a conquistar sua autonomia, serve na verdade aos interesses dos inimigos da liberdade sexual. Como mulheres, não nos reconhecemos nesse feminismo que, para além da denúncia do abuso de poder, assume as feições do ódio contra os homens e a sexualidade. Nós acreditamos que a liberdade de dizer não a uma proposta sexual não existe sem a liberdade de importunar. E consideramos que é preciso saber responder a essa liberdade de importunar de outra maneira que não seja se fechar no papel de presa (Manifesto Catherine Deneuve et al., grifo nosso).

Ao estabelecer a temática do assédio alinhada a novas categorias semânticas, tais como, "liberdade de importunar" e "liberdade sexual", o referido manifesto promove a recategorização deste fenômeno discursivo, propondo novos contornos temáticos e figurativos à isotopia antes estabelecida. Para além de se posicionar em relação de polarização ao fio discursivo determinado pela \#metoo, o manifesto se constrói a partir da des-memória, uma vez que a própria "memória não é somente conservação e retransmissão, ela é também modificação, falsificação e disparição" (PAVEAU, 2013, p. 119).

De modo mais abstrato, os discursos que se construíram em torno da \#metoo \#eutambém concretizaram o nível do discurso, tendo como categoria de base a oposição semântica liberdade vs. opressão. A categoria opressão se encontra, portanto, alinhada ao ser mulher, que concretiza a temática do assédio a partir do medo em cada relato de situação vivenciada (consultar Figura 2 acima); e a categoria liberdade alinhada ao ser homem, tal como no excerto do Manifesto redigido pelas atrizes francesas.

De um lado, o ciberfeminismo se apropriou da \#metoo \#eutambém \#balancetonporc (respectivamente em inglês, português e francês) como forma de denúncia não somente do assédio sofrido pela atriz hollywoodiana, mas como espaço de mobilização social do feminismo em rede a favor da maior equidade entre homens e mulheres e denúncia do patriarcado, que ainda assola a sociedade contemporânea. A partir da mobilização da memória discursiva do assédio, a hashtag provocou a ascensão deste tema no debate público.

Por outro lado, o manifesto das atrizes francesas procurou concretizar de modo diferente sua visão acerca da hashtag e da temática mais ampla por ela encarnada. A partir da "liberdade de importunar" e da "liberdade sexual", o manifesto se instaurou em uma desmemória discursiva em relação à temática do assédio, na medida em que procurou ressemantizar o uso da hashtag enquanto "febre" que "provocou na imprensa e nas redes sociais uma campanha de denúncia e acusação pública de indivíduos [...] sem que lhes 
tenha sido dada a oportunidade de responder ou de se defender" (Manifesto Catherine Deneuve et al.).

A mobilização da memória ou da des-memória discursiva pode ser comprovada a partir de uma temática ampla - o assédio sexual, por exemplo - que se irradia nos discursos a partir de uma categorização de base - liberdade vs. opressão tematizada e figurativizada de modos distintos. Nos relatos das internautas a partir de uma isotopia da ameaça, do medo, enfım, da opressão; no Manifesto francês enquanto privação de uma liberdade (masculina).

Verifica-se, como fator de argumentação para cada posicionamento em relação ao tema determinado pelo assédio, a determinação ainda de papéis sociais a serem desempenhados por mulheres e homens. Na mobilização da memória do assédio sexual pela \#metoo temos a defesa de um sujeito do sexo feminino que exerce pleno direito sobre seu corpo, ao passo que na des-memória discursiva, que nega o tema do assédio sexual, promovida pelo Manifesto, é construída a imagem da mulher/sujeito que sofre o assédio como aquele que inibe o direito do Outro (assediador).

A polarização discursiva e ideológica em relação ao tema do assédio sexual é erigida a partir da relação entre os dois discursos - aqueles que mobilizam a \#metoo validando sua temática ampla e aqueles que se opõem a ela - os quais, a partir da memória e desmemória discursivas erigem ainda uma visão específica acerca da imagem da mulher e do homem na sociedade.

Se nos discursos que se inscrevem na memória discursiva do assédio, mobilizando a \#metoo, as mulheres são vistas enquanto dotadas de voz e de vontade própria para participar de uma mobilização social na internet - lembremos a convocação que a hashtag faz para que mulheres compartilhem suas experiências -; no discurso do Manifesto ela é alçada à posição de inibidora do direito do Outro, "inimigas da liberdade sexual" e "justiceiras expeditivas" que "castigam homens":

Essa justiça expeditiva já fez suas vítimas, homens castigados no exercício de sua profissão, forçados a se demitir, etc., quando seu único erro foi ter tocado um joelho, tentado roubar um beijo, falar sobre coisas "íntimas" em um jantar profissional ou ter mandado mensagens com conotação sexual a uma mulher cuja atração não era recíproca. (Manifesto Catherine Deneuve et al., grifo nosso). 


\section{Memória, des-memória e polêmica}

De acordo com Maingueneau (2008, p. 99), "o espaço discursivo é considerado como rede de interação semântica, ele define um processo de interincompreensão generalizada, a própria condição de possibilidade das diversas posições enunciativas" . Isto significa afirmar que cada enunciador cria seu discurso de acordo com as regras de sua formação discursiva na mesma medida em que não compartilha os enunciados do Outro.

A polêmica como interincompreensão é instaurada quando "cada um dos posicionamentos se define por uma relação regrada com outros, cuja identidade é tacitamente conservada" (MAINGUENEAU; CHARAUDEAU, 2008, p. 380). A partir da breve depreensão de temas e figuras que concretizam o discurso acerca da temática do assédio sexual, vislumbramos como posições enunciativas diversas categorizam a realidade, por meio da linguagem, de modos diferentes.

Dessa maneira, a polêmica se instaura, portanto, não só como controvérsia, mas como fenômeno mais geral resultante da relação entre duas formações discursivas que se ancoram em interdiscursos distintos e que concretizam seus temas de modos diversos. Essa diversidade político ideológica, fundada na partilha de determinados valores concretiza, no nível do enunciado, a polêmica como interincompreensão, na medida em que é "a semântica dos discursos que comanda a maneira pela qual os discursos se polemizam" (MAINGUENEAU, 2008, p. 107).

A temática do assédio mobilizada pela \#metoo \#eutambém foi semantizada de variadas maneiras, se ancorando em diferentes memórias e des-memórias. Na mobilização da memória discursiva do assédio encarnada na hashtag, observamos o sujeito que toma o ambiente virtual como espaço de mobilização social e que se posiciona a favor da denúncia da violência e do empoderamento, tendo, como consequência, uma imagem de mulher socialmente ativa. No Manifesto de Deneuve et al., há a mobilização da desmemória discursiva do assédio na tentativa de recategorização do acontecimento fundado pela hashtag a partir do tema da "liberdade sexual". Nele, a imagem de mulher é estabelecida de acordo com o Outro socialmente pleno, este sim dotado da "liberdade de importunar". Há, portanto, também um processo de recategorização do agressor.

A polêmica se estabelece, verdadeiramente, desde os valores de base que fundamentam os dois discursos: liberdade vs. opressão. De um lado, a concretização semântica da temática do assédio sexual, por parte das internautas pela mobilização da \#metoo \#eutambém, é orientada pela opressão sofrida pelas mulheres e a consequente busca de maior liberdade. De outro, o Manifesto das atrizes francesas é norteado pela liberdade dos homens, os quais, quando acusados de assédio, são privados deste valor. 
A tensão entre liberdade vs. opressão se espalha pelo discurso se disseminando semanticamente de formas variadas, porém o mais relevante está na categorização que estes valores propõem em relação aos papéis sociais de gênero. Se de um lado - na mobilização feminista da hashtag - a imagem das mulheres é erigida nos discursos a partir da luta contra o silenciamento; de outro é imputado a elas a obrigação de manter este silêncio em prol da "liberdade de importunar" masculina. A polêmica surge daí enquanto interincompreensão visto que

[...] o caráter constitutivo da relação interdiscursiva faz aparecer a interação semântica entre os discursos como um processo de tradução, de interincompreensão regrada. Cada um conduz o Outro em seu fechamento, traduzindo seus enunciados nas categorias do Mesmo e, assim, sua relação com esse Outro se dá sob a forma do 'simulacro' que dele constrói. (MAINGUENEAU, 2008, p. 22).

A interincompreensão pode ser entendida enquanto incompatibilidade entre duas posições discursivas, uma vez que a identidade de um discurso é estabelecida a partir da oposição na rede discursiva na qual é apreendida. A temática do assédio sexual, que permeia tanto as mobilizações ciberfeministas da hashtag \#metoo \#eutambém como o Manifesto de Deneuve et al. coincide com a impermeabilidade (relativa) que as duas posições ideológico-discursivas encarnam. O sentido é, entre elas, construído como malentendido, uma vez que estas posições permanecem relativamente polarizadas, isto é, não compartilhando nem os mesmos valores de base, nem os mesmos processos de tematização e figurativização discursivas.

A interincompreensão se dá porque o dizível de um campo de discurso dado é governado por um sistema de restrições único que deve ser concebido como uma competência discursiva. A competência discursiva corresponde à aptidão que deve ter um sujeito para produzir enunciados que dependem de uma formação discursiva determinada. Adicionalmente, deve reconhecer a incompatibilidade semântica de enunciados das formações discursivas que constituem seu Outro e interpretar, traduzir, esses enunciados nas categorias de seu próprio sistema de restrições.

A mobilização social das hashtags que gera, do ponto de vista discursivo, uma polêmica como interincompreensão, reinsere o tema do assédio no debate público fazendo com que circule e solicite o posicionamento do sujeito social. Mobilizar então a memória ou a des-memória, neste processo, tanto revela determinado ponto de vista, quanto inscreve o discurso e o sujeito em determinada comunidade discursiva.

Além disso, cada posicionamento erige uma imagem de mulher - menos ou mais empoderada no cenário social. A polêmica gerada em torno da hashtag contribui, portanto, com o debate da agenda feminista, que procura cada vez mais se utilizar das ferramentas 
do ciberespaço para instigar o questionamento em torno da equidade entre os gêneros. Ademais, promove reflexão em torno de significações que se constroem discursivamente em torno das figuras de gênero - feminino e masculino - e seus papéis sociais, a partir de temas que englobam este paradigma, tal como o assédio sexual.

É importante salientar, na esteira do coletivo Alliance des femmes pour la démocratie (2019, p. 43), que o movimento \#metoo \#eutambém "se inscreve numa continuidade, uma evidente genealogia, como um momento crítico, uma etapa importante daquilo que Antoinette Fouque chamou, há algumas décadas, de 'a mais longa da revoluções': aquela das mulheres" ${ }^{21}$. Essa hashtag demonstra a força do momento que vivemos, de recrudescimento da consciência das mulheres em não aceitar nenhum tipo de retrocesso e, enfim, de acabar com todas as formas de subordinação resistindo na defesa dos direitos democráticos.

\section{REFERÊNCIAS}

ALLIANCE DES FEMMES POUR LA DÉMOCRATIE. \#MeToo, une étape décisive dans la longue marche des femmes pour leur libération. In: LEQUETTE, S.; LE VERGOS, D. Cours petite fille! \#metoo \#timesup \#noshamefist. Paris: Éditions des femmes Antoinette Fouque, 2019.

BARROS, D. L. P. Estudos do discurso. In: FIORIN, K. L. (org.). Introdução à Linguística II: princípios e procedimentos. São Paulo: Editora Contexto, 2011.

CASTELLS, M. La galaxia Internet. Barcelona: Plaza \& Janés Editores, S.A, 2001.

CASTELLS, M. Redes de indignação e esperança: movimentos sociais na internet. Tradução Carlos Alberto Medeiros. Rio de Janeiro: Zahar, 2017.

COLLADO, A. M.; NAVARRETE, A. Ciberfeminismo: também uma forma de ativismo. 2006. Disponível em: http://www.rizoma.net/interna.php?id=220\&secao=desbunde. Acesso em: 25 mai. 2017.

DEIBERT, R. J. International plug'n play? Citizen activism, the Internet, and the global public policy. International Studies Perspectives, v. 1, p. 255-272, 2000.

DISCINI, N. A Comunicação nos textos. São Paulo: Contexto, 2007.

21 Antoinette Fouque. Geste des femmes. Prefácio do Dictionnaire universel des créatices. Paris, 2013. 
FACURI, C. et al. Violência sexual: estudo descritivo sobre as vítimas e o atendimento em um serviço universitário de referência no Estado de São Paulo, Brasil. Cad. Saúde Pública, Rio de Janeiro, v. 29, n. 5, p. 889-898, mai. 2013.

FIORIN, J. L. Elementos de Análise do Discurso. São Paulo: Contexto, 2009.

FIORIN, J. L. Linguagem e Ideologia. São Paulo: Ática, 2004.

HARAWAY, D. Manifesto ciborgue: ciência, tecnologia e feminismo-socialista no final do século XX. In: SILVA, T. T. da. (org.). Antropologia do ciborgue. Belo Horizonte: Autêntica, 1984. p. 37-129.

HIRATA, H. et al. (org.). Dicionário crítico do feminismo. São Paulo: Editora UNESP, 2009.

LALONDE, J. Abécédaire du Web: 26 concepts pour comprendre la création sur Internet. Quebéc: Presses Universitaires du Quebéc (PUQ Nulérique), 2012.

LÉVY, P. Cibercultura. São Paulo: Editora 34, 1999.

MANIFESTO CATHERINE DENEUVE et al. El País Brasil. A íntegra do manifesto assinado por Catherine Deneuve. Disponível em: https://brasil.elpais.com/brasil/2018/01/12/ opinion/1515792486_891199.html. Acesso em: 31 out. 2018.

MAINGUNENEAU, D. Gênese dos discursos. Tradução Sírio Possenti. São Paulo: Parábola Editorial, 2008.

MAINGUENEAU, D.; CHARAUDEAU, P. Dicionário de Análise do discurso. São Paulo: Editora Contexto, 2008.

ORLANDI, E. Análise do Discurso: princípios e procedimentos. Campinas: Pontes, 2007.

PAVEAU, M-A. L'Analyse du discours numérique. Dictionnaire des formes et des pratiques. Paris: Hermann, 2017.

PAVEAU, M-A. Linguagem e Moral: uma ética das virtudes discursivas. Tradução Ivone Benedetti. Campinas: Editora da UNICAMP, 2015. 
PAVEAU, M-A. Os pré-discursos: sentido, memória e cognição. Tradução Graciely Costa e Débora Massman. Revisão de tradução José Horta Nunes. Campinas: Pontes Editores, 2013a.

PAVEAU, M-A. Memória, des-memória, a-memória: quando o discurso volta-se para seu passado. Tradução Jocilene Santana Prado; Eduardo Lopes Piris. EID\&A - Revista Eletrônica de Estudos em Discurso e Argumentação, Ilhéus, n. 5, p. 137-161, dez. 2013b.

RAGO, M. Trabalho feminino e sexualidade. In: DEL PRIORE, M. (org.). BASSANEZI, C. (coord. de textos). História das mulheres no Brasil. São Paulo: Contexto, 1997. p. 578-606.

RIGITANO, M. E. C. Redes e ciberativismo: notas para uma análise do centro de mídia independente. BOOC - Biblioteca on-line de ciências da comunicação. Disponível em: http://www.bocc.ubi.pt/_esp/autor.php?codautor=890\#topo. 2003 [não paginado]. Acesso em: 04 out. 2018. 